\title{
METASTATIC MELANOMA PRESENTING AS UNDIFFERENTIATED TUMOUR OF UNKNOWN PRIMARY SITE: AN IMMUNOHISTOCHEMICAL ALGORITHM
}

\section{Leila ALI ${ }^{1}$, Valentin MOLDOVAN ${ }^{1 凶}$, Diana DEREWICZ ${ }^{3,4}$, Octav GINGHINA ${ }^{3}$, Maria SAJIN ${ }^{2,3}$, Mariana COSTACHE ${ }^{2,3}$}

${ }^{1}$ Department of Pathology, National Institute of Pathology „Victor Babes“, Bucharest, Romania

${ }^{2}$ Department of Pathology, University Emergency Hospital, Bucharest, Romania

${ }^{3}$ University of Medicine and Pharmacy „Carol Davila“, Bucharest, Romania

${ }^{4}$ „M. S. Curie“ Clinical Emergency Hospital for Children, Bucharest, Romania

Received 09 Oct 2019, Accepted 14 Nov 2019

https://doi.org/10.31688/ABMU.2019.54.4.08

\section{Abstract}

Introduction. The identification of the type and site of origin in undifferentiated tumours of unknown primary site using immunohistochemistry is a frequent requirement in pathology practice. There are many histologic lesions that display similar morphologic aspects, with misdiagnosis potentially resulting in overor undertreatment. This makes the diagnostic accuracy extremely important in the era of targeted therapies. The objective of the study was to evaluate the process of diagnosis in 50 melanoma cases presenting as poorly differentiated or undifferentiated tumours with unknown primary origin, with emphasis on the immunohistochemical algorithm.

Methods. 50 cases were selected to analyse the utility of IHC testing in diagnosing poorly differentiated malignancies. The immunohistochemical evaluation was based on the staining percentage of cells: focal positive $<50 \%$, diffuse positive $>50 \%$, negative (-) $0 \%$.

\section{RÉsumé}

Mélanome métastatique ayant l'aspect d'une tumeur non différenciée de site primaire inconnu: un algorithme immunohistochimique

Introduction. L'identification par immunohistochimie du type et du site d'origine dans les tumeurs non différenciées de site primaire inconnu est une exigence fréquente dans la pratique pathologique. Il existe de nombreuses lésions histologiques montrant des aspects morphologiques similaires, avec un diagnostic erroné pouvant entraîner un traitement insuffisant ou excessif. Cela rend la précision du diagnostic extrêmement importante à l'ère des thérapies ciblées.

L'objectif de l'étude était d'évaluer le processus de diagnostic dans 50 cas de mélanome présentant des tumeurs peu différenciées ou non différenciées d'origine primaire inconnue, l'accent étant mis sur l'algorithme immunohistochimique. 
Results. After applying the Fan Lin algorithm, for most of the cases (45), the cytokeratin and CD45 proved negative, while $\mathrm{S} 100$ and vimentin were positive in diffuse or zonal patterns. For the 3 cases analysed by applying the Turin algorithm, the first antibody panel consisted in testing CK7/CK20, that showed no expression for all 3 cases.

Conclusions. In this study, we demonstrated that the immunohistochemical examination of poorly differentiated malignant tumours is a reliable and valuable test and is recommended as a standard method in diagnosis along with the correlations with clinical and histological data.

Keywords: metastatic melanoma, undifferentiated tumour, immunohistochemistry algorithm.

\section{Abbreviations list \\ IHC - immunohistochemistry \\ HE - hematoxylin-eosin \\ PCR - polymerase chain reaction}

\section{INTRODUCTION}

Melanoma accounts for only $1 \%$ of all skin cancers, but most of skin cancer deaths $(75 \%)^{1}$. It is regarded as an aggressive malignancy considering the phenotypic variety and loss of differentiation markers. Less than $10 \%$ of all melanoma patients present with unknown primary tumour site ${ }^{2}$. Taking into consideration that tumours of unknown primary site represent up to $5 \%$ of all cancers and are among the top six causes of cancer deaths $s^{3-5}$, an accurate diagnostic decision is crucial as treatment approaches are fundamentally distinct for different types of tumor ${ }^{6}$.

THE OBJective OF THE STUDY was to analyse the management of undifferentiated unknown primary site tumours from the pathologist point of view and assess the essential features distinguishing malignant melanoma from other histologic mimics, with emphasis on the immunohistochemical algorithms useful in diagnosis.

\section{Material AND methods}

We selected 67 cases addressed in 2018 as undifferentiated neoplasm, regardless of site, age and gender, with no prior known malignancies, from the digital registry record of the National Institute of Pathology „Victor Babes“, Bucharest, Romania. The cases were referred to the Pathology Department for immunohistochemistry (IHC) testing with the
Méthodes. 50 cas ont été sélectionnés pour analyser l'utilité des tests IHC dans le diagnostic de tumeurs malignes différenciées. L'évaluation immunohistochimique était basée sur le pourcentage de coloration des cellules: positif positif $\langle 50 \%$, positif positif diffus $>$ $50 \%$, négatif (-) $0 \%$.

Résultats. Après application de l'algorithme de Fan Lin, dans la plupart des cas (45), la cytokératine et le CD45 ont donné des résultats négatifs, tandis que S100 et la vimentine étaient positifs selon un modèle diffus ou zonal. Pour les 3 cas analysés en appliquant l'algorithme de Turin, le premier panneau d'anticorps consistait dans un test CK7 / CK20, qui n'a montré aucune expression pour les 3 cas.

Conclusions. Dans cette étude, nous avons démontré que l'examen immunohistochimique de tumeurs malignes faiblement différenciées est un test fiable et précieux. Il est recommandé comme une méthode standard de diagnostic, ainsi que les corrélations avec les données cliniques et histologiques.

Mots-clés: mélanome métastatique, tumeur non différenciée, algorithme d'immunohistochimie.

purpose of finding the primary tumour site or for a second opinion. The slides were re-evaluated by two experienced pathologists. After the revision, 50 cases were selected and the final diagnosis for all 50 cases were malignant melanoma.

We analysed the utility of IHC testing and how it becomes a necessary tool in diagnosing poorly differentiated malignancies, by following the diagnostic procedures for the selected cases.

For each case the clinical and pathological reports were submitted, along with the paraffin-embedded tissue. The paraffin blocks were sectioned at 3 $\mu \mathrm{m}$ thickness. One slide was stained with hematoxylin-eosin (HE) and further slides were processed by IHC testing.

For immunostaining, deparaffinized and rehydrated sections were heat-treated to retrieve antigenic activity. Endogenous peroxidase was inhibited with $0.3 \%$ hydrogen peroxide. The sections were incubated using commercially available antibodies. The colour was developed with diaminobenzidine or Fast Red, followed by hematoxylin counterstaining. The antibody panel composition was determined based on the clinical data, original diagnosis and site for each case. Appropriate positive and negative controls were also used. The immunohistochemical evaluation was based on the staining percentage of cells: focal positive $<50 \%$, diffuse positive $>50 \%$, negative (-) $0 \%$. The slides were examined under a light microscope (Leica DM750, Leica Microsystems, Wetzlar, Germany). 


\section{Tumor locations in the studied group}

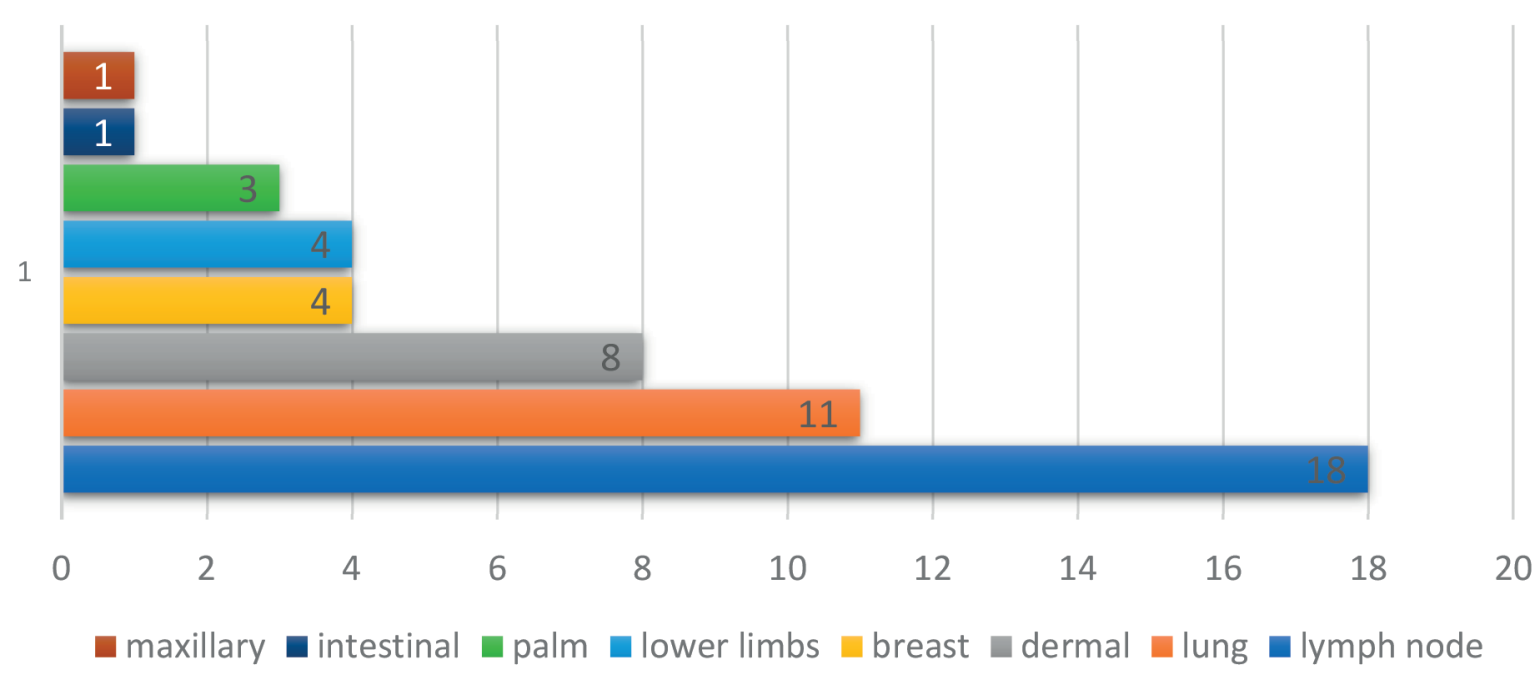

Fig.1. Tumor locations in the studied group

\section{Results}

The majority of patients were females (60\%), and the age range was between 41 and 86 years. In terms of primary tumour location, 4 cases presented as breast tumours, 3 brain tumours, 11 lung tumours, 1 intestinal tumour, 1 maxillary sinus tumour, 4 lower limb tumours, 18 lymph node metastases, 8 intradermic tumours (Fig. 1).

The Fan Lin algorithm ${ }^{5}$ used for diagnostic approach of the tumours recommends the following:

1. Reviewing the HE slides.

2. Considering the basic clinical information (age, sex, tumour location, and prior malignancy).

3. Re-evaluating the morphologic features of the tumour and predicting the most likely category (carcinoma, melanoma, sarcoma, lymphoma, or germ cell tumour).

4. Determining the first IHC panel to order.

5. Additional to Fan Ling algorithm ${ }^{7}$, for the examined lot, a second staining was used with the purpose of securing the first panel's findings.

In the attempt to extract useful clues regarding the cell of origin, the morphological examination of the tumours on HE stain showed the following: in 47 cases it was a lack of relationship with the epidermis, the tumours had poorly differentiated proliferations, with no specific architectural features, mostly composed of sheets of atypical epithelioid cells or, much more rarely, spindle cells mixed with epithelioid cells comprising necrotic regions. There was a lack of typical growth patterns or morphological signs of differentiation, showing no diagnostic features and no attributes suggestive for a primary site. Four cases (2 lymph node metastases, 1 breast tumour and 1 skin metastasis) showed morphological differentiation clues as presented in Table 1 .

The clinical information was mostly minimal, with no data on prior known malignancies. The first step in the IHC evaluation is to confirm the tumour lineage ${ }^{8}$ (epithelial, mesenchymal or melanocytic) us-

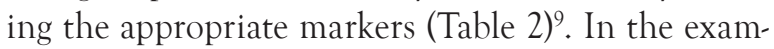
ined lot, we proceeded accordingly:

- the Fan Ling algorithm was applied for the 46 cases classified as undifferentiated tumours and for the case with brown pigmentation, using the 4-antibody panel, with expected positive and negative staining (Table 3), thus avoiding a false result in the case of aberrant expressions ${ }^{10}$;

Table 1. Morphological differentiations in 4 cases from the selected lot.

\begin{tabular}{ccc}
\hline Case presentation & Morphologic clue & Suggested tumor type \\
\hline lymph node metastasis & brown pigment deposits (Fig. 4) & melanoma \\
\hline lymph node metastasis & signet ring cells (Fig 2.A) & adenocarcinoma \\
\hline breast tumor & scattered tubules (Fig. 3) & adenocarcinoma \\
\hline skin metastasis & foci of stromal mucin & carcinoma \\
\hline
\end{tabular}


Table 2. IHC markers by type

\begin{tabular}{cc}
\hline Type & IHC marker \\
\hline Epithelial markers & CAM 5.2, AE1-AE3, CK7, CK20, CEA, EMA \\
\hline Melanocytic markers & S100, HMB45, MelanA, MITF, BRAF \\
\hline Lymphoid markers & CD45, CD20 (B cells), CD3 (T cells), CD15, CD30 (Hodgkin) \\
\hline Histiocytic markers & CD68, CD1a \\
\hline Neuroendocrine markers & Vimentin, CD31, CD34, D2-40, SMA, desmin \\
\hline Mesenchymal markers
\end{tabular}

Table 3. IHC panel for staining the undifferentiated tumors - Fan Lin algorithm

\begin{tabular}{cccccc}
\hline Cell type & IHC marker & Specificity & Producer & Dilution & Clone \\
\hline Epithelial & AE1/AE3 & Pan cytokeratin & $\begin{array}{c}\text { Abcam, Cambridge, } \\
\text { MA, USA }\end{array}$ & $1: 50$ & ab1747070 \\
\hline Melanocytic & S100 & Human S-100 protein & $\begin{array}{c}\text { Leica Microsystems, } \\
\text { Wetzlar, Germany }\end{array}$ & $1: 40$ & S1/61/69 \\
\hline Lymphoid & CD45 & $\begin{array}{c}\text { Receptor-type tyros- } \\
\text { ine-protein phosphatase } \\
\text { C }\end{array}$ & $\begin{array}{c}\text { Dako Omnis, Agilent, } \\
\text { Santa Clara, CA, USA }\end{array}$ & $1: 100$ & 2B11+PD7/26 \\
\hline Mesenchymal & Vimentin & Vimentin & $\begin{array}{l}\text { Dako Omnis, Agilent, } \\
\text { Santa Clara, CA, USA }\end{array}$ & $1: 1000$ & V9 \\
\hline
\end{tabular}

Table 4. IHC panel for carcinomatous origin - Turin algorithm

\begin{tabular}{ccccc}
\hline IHC marker & Specificity & Producer & Dilution & Clone \\
\hline CK7 & $\begin{array}{c}\text { Keratin, type II cy- } \\
\text { toskeletal 7 }\end{array}$ & $\begin{array}{c}\text { Dako Omnis, Agilent, Santa Clara, CA, } \\
\text { USA }\end{array}$ & $1: 100$ & OV-TL 12/30 \\
\hline CK20 & $\begin{array}{c}\text { Keratin, type I cytoskel- } \\
\text { etal 20 }\end{array}$ & $\begin{array}{c}\text { Dako Omnis, Agilent, Santa Clara, CA, } \\
\text { USA }\end{array}$ & $1: 600$ & Clone Ks20.8 \\
\hline PSA & 34 kD protein & Leica Microsystems, Wetzlar, Germany & $1: 200$ & 35 H9 \\
\hline MelanA & $\begin{array}{c}\text { Melanoma antigen rec- } \\
\text { ognized by T-cells 1 }\end{array}$ & $\begin{array}{c}\text { Dako Omnis, Agilent, Santa Clara, CA, } \\
\text { USA }\end{array}$ & 1:50 & Clone A103 \\
\hline Vimentin & Vimentin & Dako Omnis, Agilent, Santa Clara, CA, \\
USA
\end{tabular}
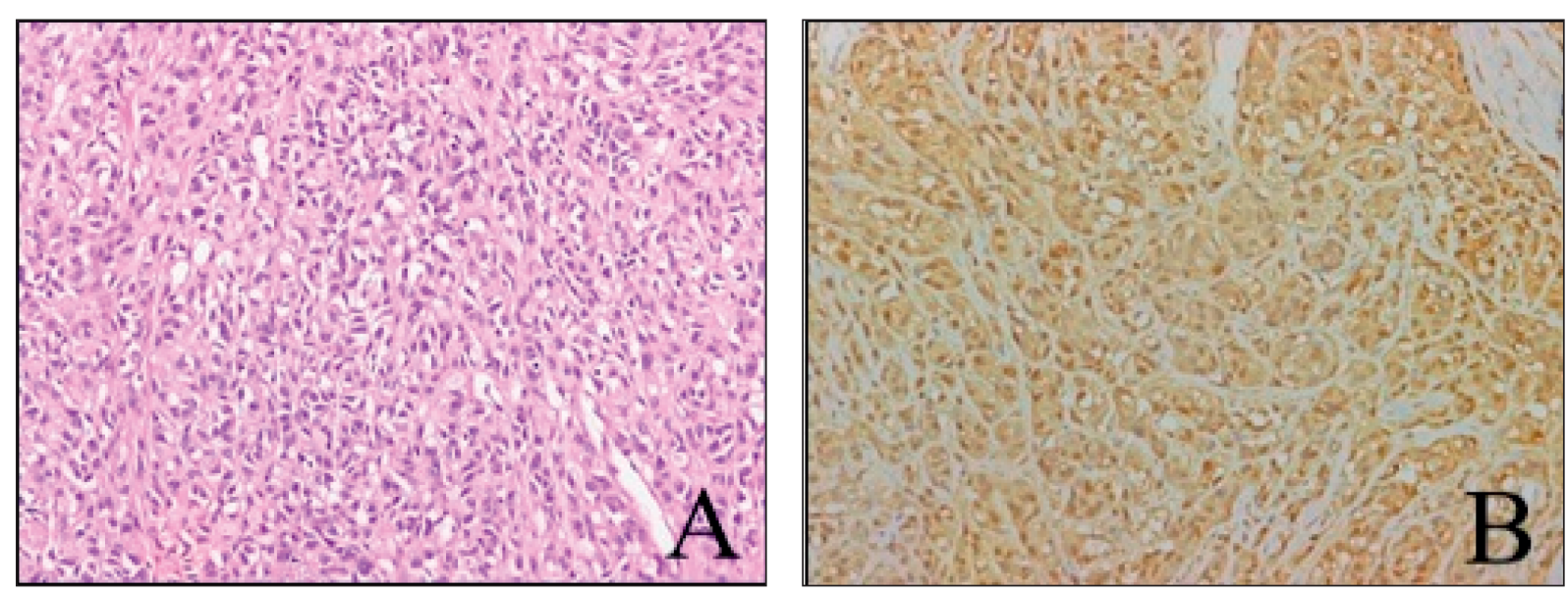

Fig 2. (A, B) Epithelioid proliferation with signet ring cells A. HE stain, 200x magnification. B. S100 stain, 200x magnification 


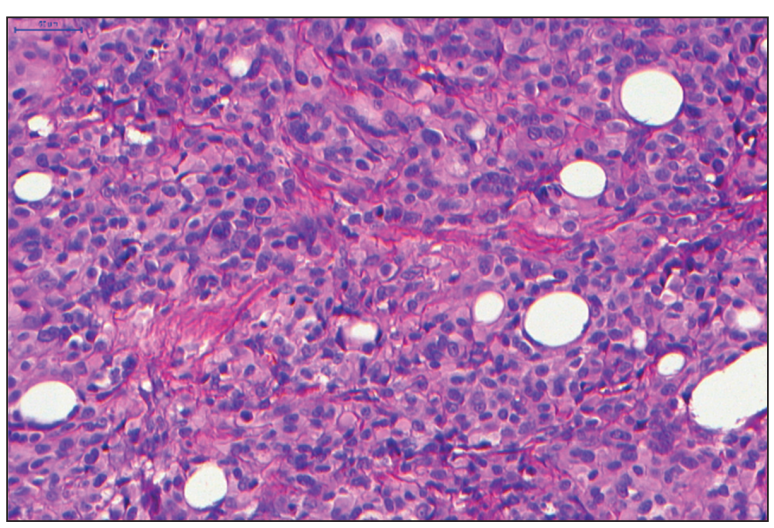

Fig 3. Epithelioid proliferation with scattered tubules, HE, 200x

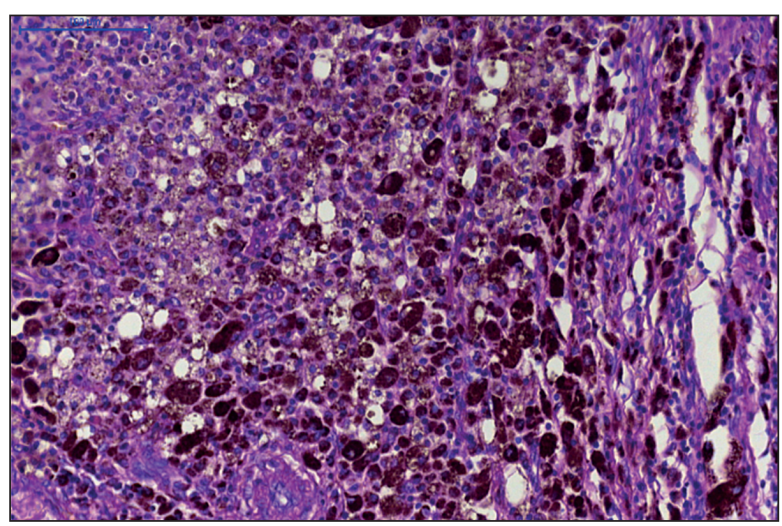

Fig 4. Pigmented lesion, HE, 200x

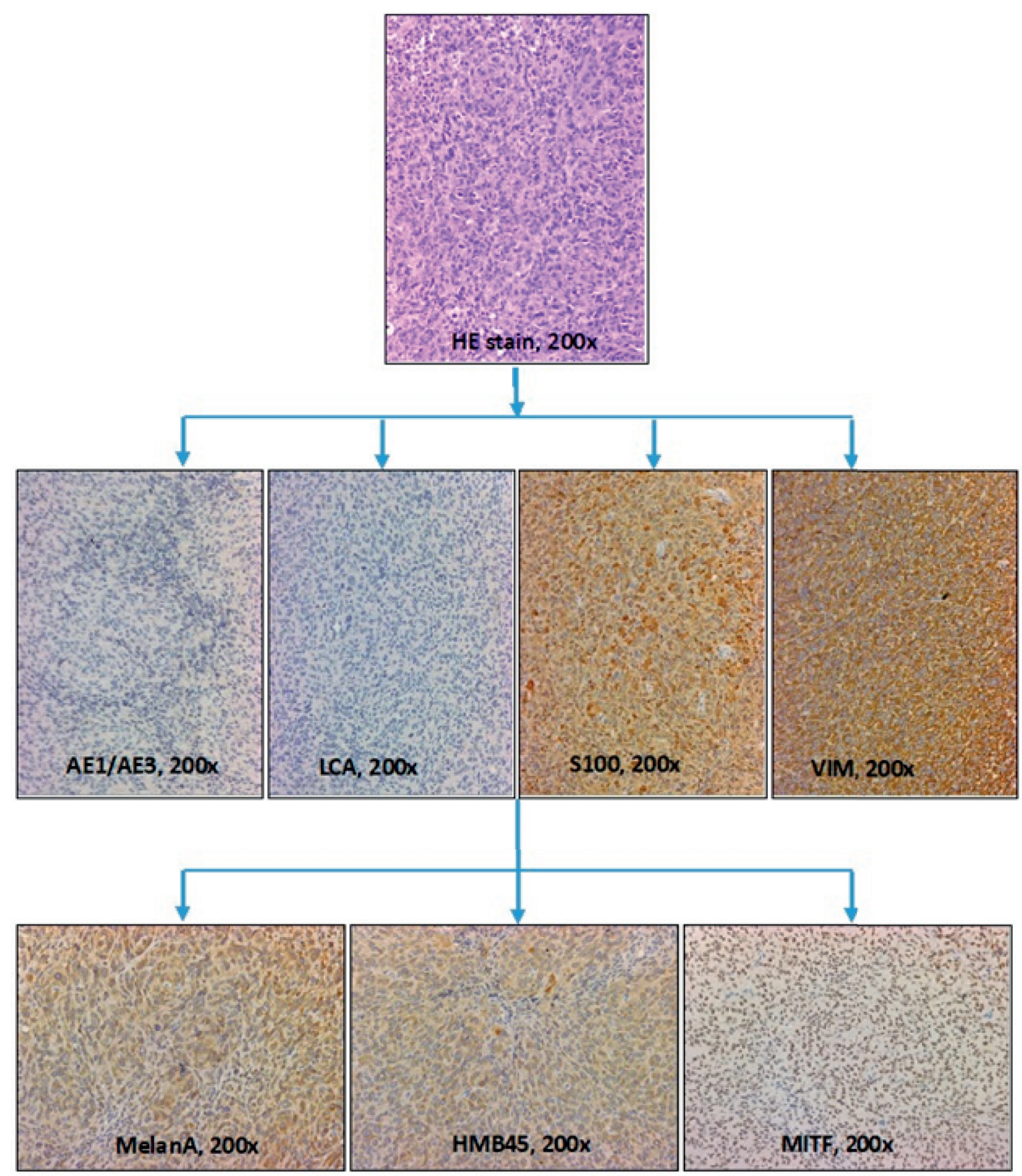

Fig 5. Fan Lin IHC algorithm staining results 
- the Turin algorithm was applied for the 3 cases with morphologic features that suggest a carcinomatous origin (Table 4).

The panels were designed using reliable markers with high sensitivity and specificity and stable clones $^{11}$. The antibody panel for the determination of tumour lineage comprised: cytokeratin AE1/AE3; S100; Vimentin; CD45. After applying the Fan Lin algorithm, for most of the cases (45), the cytokeratin and CD45 proved negative (except for one case that focally expressed cytokeratin), while S100 (Fig 2.B.) and vimentin were positive in diffuse or zonal patterns. Having established the cell of origin for most of the cases, the procedure continued with a second IHC staining adding melanocytic markers to support the obtained data, avoiding diagnostic errors in case of false positive/negative results. HMB45, MelanA and MITF were used for the final step of the procedure, with all the aforementioned antibodies positive for the entire examined lot (Fig 5).

One case proved negative for all the tested IHC markers, and after excluding a preanalytical error, the case was referred to molecular biology where a BRAF mutation was detected. For the 3 cases analysed by applying the Turin algorithm, the first antibody panel consisted in testing CK7/CK20, that showed no expression for all 3 cases. According to the algorithm, the next panel comprises testing for PSA, vimentin and MelanA. Vimentin and MelanA were diffusely positive, confirming a melanocytic origin tumour mimicking a carcinomatous morphology. An average number of 7 antibodies/case was used in the diagnostic process.

\section{Discussion}

Pathologists are seldom confronted with difficulties in the examination process of undifferentiated neoplasms, like identifying the tumour type or establishing the primary site ${ }^{12}$. It is complicated to make a diagnosis only on routinely HE stains in optical microscopy. Typically, when presented with a poorly differentiated tumour without morphologic features of lineage differentiation and/or no evident primary origin, we classify it as undifferentiated tumour of uncertain origin and follow the IHC workup.

Thereupon, after the HE examination and the study of clinical data, the first IHC panel antibodies must be selected. There are two paths that can be followed, depending on HE examination:

- either the tumour is undifferentiated, and we must include a broad category of markers to rule out carcinoma, sarcoma, melanoma or lymphoma in the differential diagnosis?

- or there are morphological features that imply a lineage differentiation, recommending specific antibodies for the site of origin (e.g., if we suspect a carcinoma, we must use cytokeratins like CK7, CK20 etc).

There are several algorithms available. If there is a suspicion of a carcinomatous origin for an unknown primary origin tumour, we have the possibility to use one of the following:

1. The 18 markers algorithm (MD Anderson) ${ }^{13}$;

2. The 12 markers algorithm (Turin, Italy) ${ }^{14}$;

3. The 15 markers algorithm (Tokyo, Japan) ${ }^{15}$;

4. The Fan Lin algorithm for undifferentiated neoplasm/tumour of uncertain origin?

The first 3 aforementioned algorithms are based on the evaluation of CK7 and CK20 with 4 phenotypes:

a. CK20+/CK7- suggestive of colon primary tumor ${ }^{7}$;

b. CK20-/CK7+ suggestive of lung, breast, ovarian, endometrial, cholangitic and pancreatic origin;

c. CK 20+/CK7+ mostly urothelial, ovarian primary tumour;

d. CK7-/CK20- hepatic, renal, prostate or squamous origin.

For an undifferentiated neoplasm, the Fan Lin approach must be used? The algorithm starts with a panel of 4 antibodies - CK, S100, vimentin, LCA intended to highlight the original cell lineage. Following this setting out phase, an additional stage to further define the tumour lineage is necessary.

The differential diagnosis must be narrowed down to 1-3 possibilities. According to Anderson et $\mathrm{al}^{9}$, pathologists can identify the tumour origin as their first choice in $50-55 \%$ of cases or as their first, second, or third choice in $67 \%$ to $74 \%$ of cases. The decisional process involves clinical data (patient's age, tumour site, evolution) and tumour histology (cytological and architectural features $)^{12}$.

From the 50 cases we analysed, 4 of them expressed specific patterns, and the rest did not, allowing us to classify most of the tumours (46) as undifferentiated, and proceed to establishing tumour cell type. Given that cytokeratins and CD45 were negative, and 45 cases were S100 and vimentin positive, a second testing followed in order to confirm the origin of the tumours. The purpose of this step is to establish the broad category of the neoplasm examined. As stated in Table 1, AE1/AE3 antibody is usually functional for identifying an epithelial lineage, but insufficient to exclude it in case of negative staining ${ }^{16}$. We must take into consideration that S100 and vimentin ${ }^{17}$, although nonspecific markers, can highlight almost all melanomas, but using CD45 alone is not enough to eliminate a hematopoietic proliferation ${ }^{18}$. 
The final step of the process must confirm the previous data and determine the diagnosis. For this outcome we must use tissue-specific markers. As the literature states, there are no antibodies entirely specific for a certain tumour ${ }^{19}$, however, there are panels where 2 or 3 antibodies are associated to support the diagnosis ${ }^{20}$.

The metastatic melanoma has many faces in terms of morphological expression and there is a high need to underline the necessity of IHC confirmation. Therefore, an accurate decision is crucial for further treatment of the patient ${ }^{6}$; in our study, 3 of the examined cases overlapped this situation.

Melanoma has a diversity of clinical, cytological and morphological characters ${ }^{8,21,22}$. The cells have various shapes, different sizes, different nuclear/cytoplasm ratio and aspects. The architectural structure has various patterns. It is difficult to differentiate melanoma from epithelial, mesenchymal or haematological tumours only by routine microscopy $y^{23}$. Consequently, immunohistochemical stains are fundamental to distinguish melanoma from other neoplastic proliferations. In addition, more issues emerge in case of spindle cell morphology or special types of melanoma like desmoplastic or dedifferentiated melanoma. There are several reports of metastatic melanoma with papillary features ${ }^{24}$, melanoma mimicking giant cell variant of glioblastoma multiforme ${ }^{25}$ or metastatic melanoma presenting as primary breast malignancies ${ }^{26}$.

It is common knowledge that with the evolution of the immunohistochemical markers, a melanoma diagnostic panel emerged, comprising antibodies as S-100 (most sensitive for melanocytic lesions), HMB-45, Melan-A, MITF, vimentin. Current studies assess that there are cases of melanomas that can display uncommon expression when performing IHC tests $^{27}$. In our group, we encountered the situation of focal cytokeratin expression in two melanomas presenting as a primary breast, and a lung tumour. There is also the situation in which melanomas no longer express specific markers ${ }^{28}$ (explained by the dedifferentiation of the lesion), like S100, frequently negative in uveal or sinonasal located melanomas ${ }^{29}$. We encountered this setting in only one case from the studied group. It had a total loss of antigenicity, confirmed as a melanoma by molecular biology, as about $50 \%$ of advanced type melanomas have BRAF mutation $^{30}$. Drugs like vemurafenib and dabrafenib target the mutated BRAF kinase, with long-term benefits $^{31}$. Biological therapies have an important role in advanced clinical stages and are recommended in the presence of potential targets (BRAF mutations) demonstrated by PCR or IHC methods ${ }^{6,32-34}$.

\section{Conclusions}

The major role for IHC in diagnosing melanocytic lesions is to determine the melanocytic nature of a given tumour and to rule out other non-melanocytic histologic mimics. Another role of IHC is to define the potential biological behaviour of a given lesion, once its melanocytic origin has been demonstrated.

In this study we demonstrated that the immunohistochemical examination of poorly differentiated malignant tumours is a reliable and valuable test and is recommended as a standard method in diagnosis along with the correlations with clinical and histological data. Particularly in the case of melanoma, the tumours must be confirmed by an IHC panel, as some of them may have aberrant expressions for other markers.

\section{Compliance with Ethics Requirements:}

„The authors declare no conflict of interest regarding this article"

'The authors declare that all the procedures and experiments of this study respect the ethical standards in the Helsinki Declaration of 1975, as revised in 2008(5), as well as the national law. Informed consent was obtained from all the patients included in the study"

"No funding for this study"

\section{REFEREnCES}

1. Gallagher RP, Elwood JM (eds): Epidemiological Aspects of Cutaneous Malignant Melanoma, Boston, MA: Springer US; 1994:[3 June 2018]. Available at: http://link.springer. com/10.1007/978-1-4615-2626-1

2. Cancer Research UK. Cancer Statistics for the UK. [14 August 2019]. Available at: https://www.cancerresearchuk. org/health-professional/cancer-statistics/statistics-by-cancer-type/melanoma-skin-cancer.

3. Riihimäki M, Hemminki A, Sundquist K, Hemminki K. Causes of death in patients with extranodal cancer of unknown primary: searching for the primary site. BMC Cancer 2014;14:439.

4. Bratu OG, Marcu RD, Socea B, et al. Immunohistochemistry particularities of retroperitoneal tumors. Rev Chim (Bucharest) 2018;69(7):1813-1816.

5. Iorga L, Anghel R, Marcu D, et al. Renal sarcoma - a rare parenchymal tumor with a very poor prognosis. Arch Balk Med Union 2018;53(3):434-438.

6. Garbe C, Peris K, Hauschild A et al. Diagnosis and treatment of melanoma. European consensus-based interdisciplinary guideline - Update 2016. European Journal of Cancer 2016;63:201-217.

7. Lin F, Liu H. Immunohistochemistry in undifferentiated neoplasm/tumor of uncertain origin. Archives of Pathology $\mathbb{E}$ Laboratory Medicine 2014;138(12):1583-1610. 
8. Smoller BR, Hiatt KM. Histologic Mimics of Malignant Melanoma, in Epidermal Cell Tumors: The Basics, Smoller BR, Hiatt KM (eds). Boston, MA: Springer US; 2011:33-46.

9. Anderson GG, Weiss LM. Determining tissue of origin for metastatic cancers: meta-analysis and literature review of immunohistochemistry performance. Applied Immunohistochemistry $\mathcal{E}$ Molecular Morphology 2010;18(1):3-8.

10. Hewitt SM, Baskin DG, Frevert CW, Stahl WL, Rosa-Molinar E. Controls for Immunohistochemistry. Journal of Histochemistry and Cytochemistry 2014;62(10):693697.

11. The Human Protein Atlas. https://www.proteinatlas.org/ (Accessed on September 20, 2019)

12. Sheahan K, O'Keane JC, Abramowitz A, et al. Metastatic adenocarcinoma of an unknown primary site: a comparison of the relative contributions of morphology, minimal essential clinical data and CEA immunostaining status. American Journal of Clinical Pathology 1993;99(6):729-735.

13. Varadhachary GR. Carcinoma of unknown primary origin. Gastrointestinal Cancer Research 2007;1(6):229-235.

14. Stella GM, Senetta R, Cassenti A, Ronco M, Cassoni P. Cancers of unknown primary origin: current perspectives and future therapeutic strategies. Journal of Translational Medicine 2012;10:12.

15. Hashimoto K, Sasajima Y, Ando $M$ et al. Immunohistochemical profile for unknown primary adenocarcinoma. PLOS ONE 2012;7(1):e31181.

16. Goddard MJ, Wilson B, Grant JW. Comparison of commercially available cytokeratin antibodies in normal and neoplastic adult epithelial and non-epithelial tissues. Journal of Clinical Pathology 1991;44(8):660-663.

17. Caselitz J, Jänner M, Breitbart E, Weber K, Osborn M. Malignant melanomas contain only the Vimentin type of intermediate filaments. Virchows Archiv 1983;400(1):43-51.

18. Nandedkar MA, Palazzo J, Abbondanzo SL, Lasota J, Miettinen M. CD45 (leukocyte common antigen) immunoreactivity in metastatic undifferentiated and neuroendocrine carcinoma: a potential diagnostic pitfall. Modern Pathology 1998;11(12):1204-1210.

19. Saper CB. A Guide to the perplexed on the specificity of antibodies. Journal of Histochemistry and Cytochemistry 2009;57(1):1-5.

20. Shin D, Arthur G, Caldwell C et al. A pathologist-in-the-loop IHC antibody test selection using the entropy-based probabilistic method. Journal of Pathology Informatics 2012;3:1.

21. Farah M, Nagarajan P, Torres-Cabala CA, et al. Metastatic melanoma with balloon/histiocytoid cytomorphology after treatment with immunotherapy: A histologic mimic and diagnostic pitfall. Journal of Cutaneous Pathology 2018;45(7):545-549.

22. Ribu DL, Shield PW, Bligh JF. The varied presentation of metastatic melanoma in fine needle aspiration cytology of the breast: Metastatic melanoma in breast FNA. Cytopathology 2012;23(4):256-262.

23. Bhawan J. Non-melanocytic mimics of melanocytic neoplasms: Non-melanocytic mimics of melanocytic neoplasms. Histopathology 2012;60(5):715-730.

24. Valero-Torres A, Prieto VG, Nagarajan P, et al. Metastatic melanoma with papillary features: a mimic and possible diagnostic pitfall. The American Journal of Dermatopathology 2017;39(6):468-470.

25. Arcega R, Yong WH, Xu H. Malignant melanoma mimicking giant cell variant of glioblastoma multiforme: a case report and review of literature. International Journal of Clinical and Experimental Pathology 2015;8(5):5929-5933.

26. Bacchi CE, Wludarski SC, Ambaye AB, Lamovec J, Salviato T, Falconieri G. Metastatic melanoma presenting as an isolated breast tumor: a study of 20 cases with emphasis on several primary mimickers. Archives of Pathology $\mathcal{E}$ Laboratory Medicine 2013;137(1):41-49.

27. Chen N, Gong J, Chen X, et al. Cytokeratin expression in malignant melanoma: potential application of in-situ hybridization analysis of mRNA. Melanoma Research 2009;19(2):87-93.

28. Biernacka A, Linos KD, DeLong PA, Suriawinata AA, Padmanabhan V, Liu X. A case of S-100 negative melanoma: A diagnostic pitfall in the workup of a poorly differentiated metastatic tumor of unknown origin. Cyto Journal 2016;13:21.

29. Kan-Mitchell J, Rao N, Albert DM, Van Eldik LJ, Taylor CR. S100 immunophenotypes of uveal melanomas. Investigative Ophthalmology E⿱ Visual Science 1990;31(8):1492-1496.

30. Cheng L, Lopez-Beltran A, Massari F, MacLennan GT, Montironi R. Molecular testing for BRAF mutations to inform melanoma treatment decisions: a move toward precision medicine. Modern Pathology 2018;31(1):24-38.

31. Dimitriou F, Braun RP, Mangana J. Update on adjuvant melanoma therapy. Current Opinion in Oncology 2018;30(2):118124.

32. Singh B, Salama A. Updates in therapy for advanced melanoma. Cancers 2016;8(1):17.

33. Diaconu C. Focusing on maligant tumors: September issue @ a glance. Arch Balk Med Union 2018;53(3):313-315.

34. Belciu D, Patrascu OM, Neacsu F, Diaconu CC, Bodoarca S, Costache M. Skin metastases: three-year study of 50 cases in a university center. Arch Balk Med Union 2019;54(1):97-103. 